\title{
Editorial: Applied Composite Materials is not a Journal about Certainties
}

\section{Peter W R Beaumont ${ }^{1}$}

Published online: 1 June 2020

(C) Springer Nature B.V. 2020

It is a journal about the adventure of moving in the direction of unknown applications of composites yet to be discovered, and towards a new vision of the science and technology of this class of engineering material yet to be understood let alone to be fully agreed upon.

It is obvious to me and I believe it must be to you too that our visualisation of a scientific piece of work may be quite different. The probability is that opinions between those that judge from those that perform an investigation will not be the same. To imagine things differently is simply unrealistic. After all, we see things from divergent angles and starting positions.

The beginning of my understanding of composite material science came from an extensive program of experiments to investigate the reaction between a strong fibre embedded in a soft resin. Today, young engineers have computer power at their finger tips and the need for expensive, time-consuming, large test programmes seem to them redundant.

In Applied Composite Materials journal, authors collectively produce an impressionistic map of the present state of the science and mechanics of composite materials. The one who uses a telescope from afar sees a different picture to the one who looks down a microscope up close. The wise on the other hand stand back and choose to view from a slight distance. He or she sees the composite material as a pointillistic portrait and an impressionistic picture comes clearly into focus. We should not be surprised at such diversity of opinion between author and reviewer of published work.

While an account of the established physics and fundamentals of materials science are largely uncontroversial, the paper that describes state-of-the-art research, sometimes called "cutting edge" lies at the boundary between what we have understood and what we do not yet understand, and is still far from achieving consensus between experts. This is true of all ongoing research at the frontiers of knowledge.

On behalf of the readers of ACMa and those who put pen to paper for this Journal, I welcome Professor Maria Kashtalyan of the University of Aberdeen, UK as its new Editor-in-Chief.

Peter W R Beaumont (Editor-in-Chief)

Cambridge

June 2020

\section{Peter W R Beaumont}

